\title{
Generating synthetic fjord bathymetry for coastal Greenland
}

\author{
Christopher N. Williams ${ }^{1}$, Stephen L. Cornford ${ }^{1}$, Thomas M. Jordan ${ }^{1}$, Julian A. Dowdeswell ${ }^{2}$, Martin J. Siegert ${ }^{3}$, \\ Christopher D. Clark ${ }^{4}$, Darrel A. Swift ${ }^{4}$, Andrew Sole ${ }^{4}$, Ian Fenty ${ }^{5}$, and Jonathan L. Bamber ${ }^{1}$ \\ ${ }^{1}$ Bristol Glaciology Centre, School of Geographical Sciences, University of Bristol, Bristol, UK \\ ${ }^{2}$ Scott Polar Research Institute, University of Cambridge, Cambridge, UK \\ ${ }^{3}$ Grantham Institute, and Department of Earth Science and Engineering, Imperial College London, London, UK \\ ${ }^{4}$ Department of Geography, The University of Sheffield, Sheffield, UK \\ ${ }^{5}$ Jet Propulsion Laboratory, California Institute of Technology, Pasadena, California, USA
}

Correspondence to: Christopher Williams (chris.neil.wills@gmail.com)

Received: 2 September 2016 - Published in The Cryosphere Discuss.: 7 October 2016

Revised: 21 December 2016 - Accepted: 9 January 2017 - Published: 1 February 2017

\begin{abstract}
Bed topography is a critical boundary for the numerical modelling of ice sheets and ice-ocean interactions. A persistent issue with existing topography products for the bed of the Greenland Ice Sheet and surrounding sea floor is the poor representation of coastal bathymetry, especially in regions of floating ice and near the grounding line. Sparse data coverage, and the resultant coarse resolution at the iceocean boundary, poses issues in our ability to model ice flow advance and retreat from the present position. In addition, as fjord bathymetry is known to exert strong control on ocean circulation and ice-ocean forcing, the lack of bed data leads to an inability to model these processes adequately. Since the release of the last complete Greenland bed topography-bathymetry product, new observational bathymetry data have become available. These data can be used to constrain bathymetry, but many fjords remain completely unsampled and therefore poorly resolved. Here, as part of the development of the next generation of Greenland bed topography products, we present a new method for constraining the bathymetry of fjord systems in regions where data coverage is sparse. For these cases, we generate synthetic fjord geometries using a method conditioned by surveys of terrestrial glacial valleys as well as existing sinuous feature interpolation schemes. Our approach enables the capture of the general bathymetry profile of a fjord in north-west Greenland close to Cape York, when compared to observational data. We validate our synthetic approach by demonstrating reduced overestimation of depths compared to past attempts to constrain fjord bathymetry. We also present an analysis of the spectral characteristics of fjord centrelines us-
\end{abstract}

ing recently acquired bathymetric observations, demonstrating how a stochastic model of fjord bathymetry could be parameterised and used to create different realisations.

\section{Introduction}

Bed topography provides an essential boundary for modelling ice sheet dynamics, ice-ocean interactions and fjord circulation in Greenland (e.g. Vieli and Nick, 2011; Straneo et al., 2011). This widespread need for topographic information has motivated the development of digital elevation models (DEMs) for the bed topography, which combine remote-sensing measurements of the subglacial bed with the surrounding land and sea floor (Bamber et al., 2001; Bamber et al., 2013; Morlighem et al., 2014). Each version of the Greenland "bedmap" has provided improvements in resolution and reliability, with the most recent product to combine bed elevations and bathymetry data being Bamber et al. (2013) (from here on referred to as Bed2013). The most recent Greenland-wide topography product (Morlighem et al., 2014) provides a significant improvement over previous versions towards the ice sheet margins. The development of RTopo-2 provides another response to the limitations of Bed2013 within fjord regions, with improvements being made by including new observational data (Schaffer et al., 2016). Despite these advances, and a substantial recent increase in the amount of observational data available (e.g. Jakobsson et al., 2012; Dowdeswell et al., 2014; Boghosian et al., 2015; Rignot et al., 2016), data coverage remains 

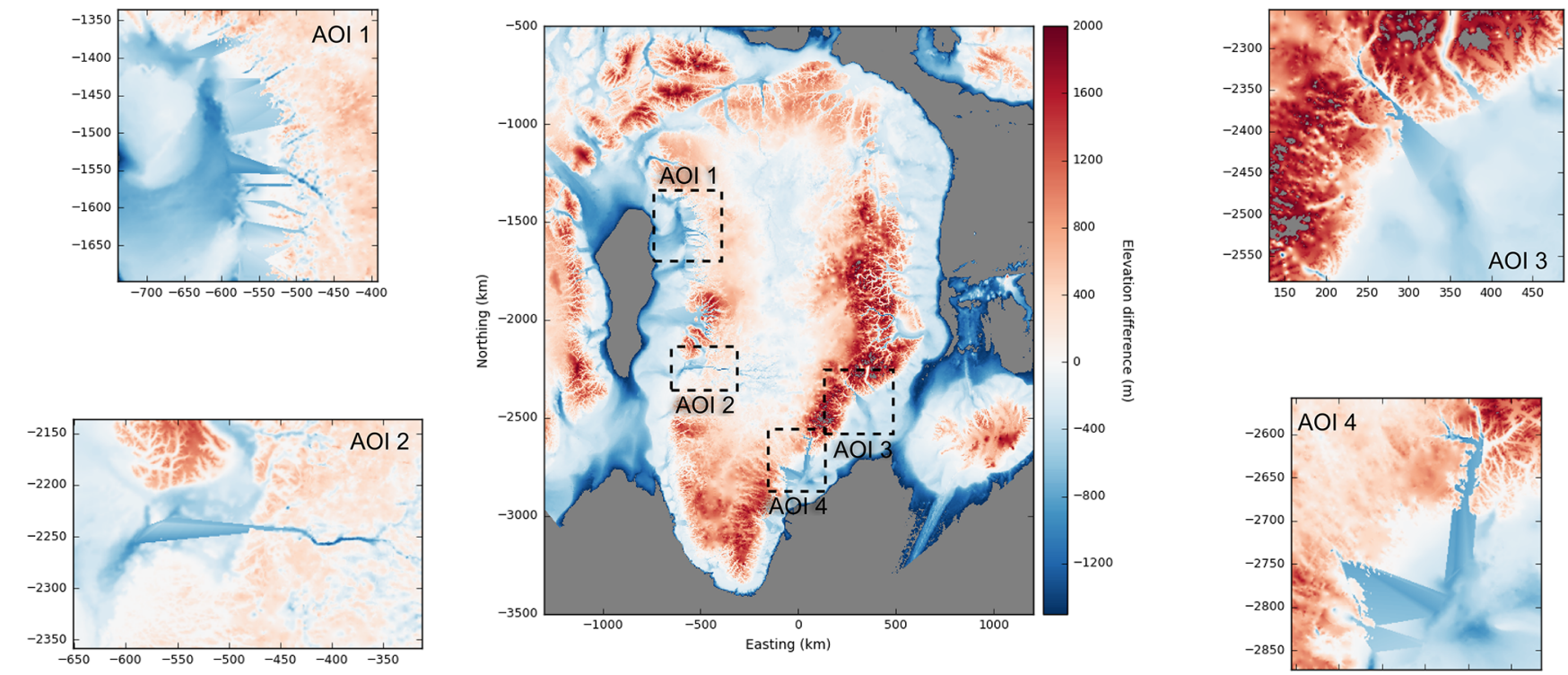

Figure 1. Examples of non-physical bathymetry around the coast of Greenland following Bamber et al. (2013), using only observations included within the IBCAO v3 (Jakobsson et al., 2012) DEM. Within the fjord mouths, discontinuities in the direction of ice flow were removed, resulting in discontinuities at the lateral boundaries.

poor for many coastal regions. As a consequence, fjord bathymetry has not, in general, been well represented, and non-physical discontinuities between land and ocean edges are apparent. In particular, in Bed2013 physically unrealistic morphologies arise at lateral boundaries of fjord mouths, as demonstrated by examples from the Greenland coast in Fig. 1.

To address these issues, the international research community has responded by collecting and compiling a wealth of new bathymetric data (e.g. Arndt et al., 2015; Boghosian et al., 2015; Rignot et al., 2016), with many other future campaigns planned (e.g. the NASA Oceans Melting Greenland (OMG) mission). It will, however, take time for extended coverage to be achieved, and some fjord regions will likely never be surveyed due to both environmental and logistical limitations associated with operating in ice-infested waters. There is, nonetheless, an urgent need to better understand and model the processes that affect the dynamics of marineterminating glaciers in Greenland and elsewhere, thus requiring fjord bathymetry to be better constrained in DEMs.

Here, we present a new methodological framework for generating geomorphologically realistic fjord bathymetry in regions of sparse observational data availability. To provide context for the introduction of our method, we first present a review of existing geostatistical approaches to interpolating channel features in DEMs (including hydrological systems, palaeo-glacial troughs and subglacial channels). In particular, we describe why these methods are ill-suited to regions where sparse observational data are available, which enables us to then demonstrate how our method provides a pragmatic solution to constraining the bathymetry of fjord systems. Our intent is that the presented approach will eventually be upscaled to all unmapped fjords along the Greenland coast. This will significantly improve existing DEMs of bed geometry beneath and at the margins of the Greenland Ice Sheet as well as its surrounding surface topography and bathymetry. A novel feature of the method, which is inspired by analogue studies of glacial troughs (Coles, 2014), is the incorporation of predefined cross-sectional channel geometry to provide a geometric structure that is physically realistic in the absence of observations, in turn providing realistic topography for applications including ice sheet modelling.

\section{Past approaches for interpolation and integration of channel geometry in DEMs}

For the purpose of integration in DEMs, fjords (Syvitski et al., 1987), river channels and glacial troughs (Batchelor and Dowdeswell, 2014) can be considered as pseudo-linear channel systems that have directional flow. In the absence of adequate direct observations, the integration of anisotropic morphology is highly desirable when interpolating channel systems in DEMs. Where observations are available, there exist methods which can interpolate additional elevations of channel features (e.g. Herzfeld et al., 2011; Goff et al., 2014). However, where there are no data available, other than the known existence of a feature (discernible from remotesensing imagery), complications arise in how to accommodate the features in DEMs. In the case of Greenland, the last data product to provide a continuous bed-to-bathymetry 
DEM (Bed2013) used different approaches to interpolate different topographic regions. Kriging interpolation was used for the interior of Bed2013. The bathymetry was taken from the International Chart of the Arctic Ocean (v3) (Jakobsson et al., 2012), referred to as IBCAO from this point forwards. The IBCAO DEM was developed from bathymetric observations using spline interpolation following Jakobsson et al. (2012). For Bed2013, triangulation (linear interpolation) was used to predict bathymetry within the fjords between the IBCAO and interior Greenland bed DEM datasets (Bamber et al., 2013), as these regions were unconstrained by observations. When traditional isotropic interpolation approaches are used, such a lack of data often results in the generation of interpolated surfaces that fail to represent true channel geometry and often appear artificially smooth. In the case of Bed2013, this problem resulted in the development of physically unrealistic topographic artefacts (Fig. 1). For methods where anisotropy is not accounted for, and where observations are only available for small regions along a channel, interpolation can result in "bulls-eye" anomalies (Dentith and Mudge, 2014), in which a channel is predicted as being a series of isolated basins (see Fig. 5a in Goff et al., 2014) as a result of clustering of the interpolation method at observation locations.

To capture the appropriate geometry of channels, several different approaches have been developed involving geometric (e.g. Goff and Nordfjord, 2004; Merwade et al., 2005), mathematical (e.g. Herzfeld et al., 2011) and mass conservation (Morlighem et al., 2014) solutions. To place our study in the context of other interpolation methods, we review previous approaches with a particular focus on resolving curvilinear features (channels). Additionally, stochastic perturbations to Greenland bed DEMs can be employed in a variety of different ice sheet modelling contexts (cf. Durand et al., 2011; Seroussi et al., 2011; Goff et al., 2014; Sun et al., 2014). It is possible that there will be a future need for similar stochastic modelling of fjord bathymetry, and we also discuss this here.

\subsection{Kriging}

The key issue with interpolating features for which orientation is important (e.g. channels) is the ability to incorporate direction into the method used to develop them from observations. Kriging - a method of interpolation for which the interpolated values are modelled by a Gaussian process - is often employed to create continuous surfaces from point data (e.g. Hock and Jensen, 1999; Bamber et al., 2001; Le Brocq et al., 2010; Bamber et al., 2013). The approach accounts for the statistical properties of observations within a local search neighbourhood using a variogram function (Deutsch and Journel, 1998). Using this, it is possible to incorporate various types of anisotropy within the basic framework (Merwade et al., 2006). However, the method only holds when applied over regions sharing the same overall statistical prop- erties whether that be, for example, the same geologic rock type or the same directional bias. When anisotropy is defined relative to a fixed Cartesian coordinate system, and where data are sparse, kriging is impractical for sinuous features with constantly varying direction such as channels (see also Fadlelmula F. et al., 2016). Specifically, dividing a region into areas of shared anisotropy (thus satisfying the assumption of stationarity within a search window) that are data sparse prevents the adequate population of the variogram with which to statistically model the region.

\subsection{Channel coordinate transformations}

To enable interpolation across channel widths, one approach uses cross-sectional profiles, but to do so, typical channel sinuosities present a problem. As an intermediary step to interpolating sinuous channels in DEMs, several approaches have been developed to transform the coordinate system of a given channel - moving from Cartesian coordinate space to channel coordinate space - enabling removal of complex sinuosity and the creation of an artificially straight channel (cf. Goff and Nordfjord, 2004; Merwade et al., 2005). Channel space (sometimes denoted as $s, n$ in the literature) differs from Cartesian space in that locations are transformed relative to their distance along the channel $(s)$ and perpendicular to the centreline $(n)$. Observations within channel space - a now-straightened channel - can be locally interpolated by considering a single direction as opposed to a continuously changing one. The interpolated channel can then be transformed back to Cartesian space. The approach breaks down, however, where multiple channels merge together at confluences. Furthermore, in the absence of sufficient observations, such an approach cannot be used alone to predict along-channel geometry without additional interpolation. For example, manual digitisation has been applied to individual channels to assist in the development of a realistic bed topography for Thwaites Glacier, West Antarctica (Goff et al., 2014). Additionally, channel straightening through coordinate transformation becomes difficult where channels manifest high levels of sinuosity or sharp changes in direction (Goff and Nordfjord, 2004).

\subsection{Mathematical morphology}

Further issues with regard to maintaining morphological characteristics of channels, in particular ensuring known depths are honoured, are apparent in low-resolution datasets particularly where interpolation methods are applied (Herzfeld et al., 2011). Where resultant data products are to be used in modelling studies, honouring known maximum depths is key as incorrect values can adversely affect results - especially with regard to maximum and minimum elevations (Herzfeld et al., 2011). To ensure true morphology is maintained, Herzfeld et al. (2011) proposed a routine which initially interpolates glacial channels along a mean direction 
vector. Connectivity between points along the trough is then established, and the locations of gridded points are adjusted to be within the vicinity of the now-defined channel. Elevations are then mapped with minimum elevations being applied to adjusted points now in the channel. This "mathematical morphological" approach is effective in regions where observations (gridded or not) covering features of interest are available. The adjustment of gridded points to follow channel directions provides a succinct approach to avoid the constraints of regular gridding, which mask channel structures especially at lower resolutions. However, observations are required to identify channels, and application of the mathematical morphology approach becomes complicated in the case of multiple interconnected dendritic type networks.

\subsection{Mass conservation}

Subglacial channels, which occur beneath grounded ice, are significantly easier to interpolate into DEMs than fjords as a mass conservation optimisation scheme can be applied (Morlighem et al., 2011, 2014). This approach is independent of traditional geostatistical interpolation methods. Bed elevation values are calculated from ice thickness values, which are derived from a combination of radar sounding measurements and surface velocity observations and of course using the assumption that mass is conserved along flow. Despite such an approach being useful for subglacial channels covered by grounded ice, this approach cannot be applied for regions of open ocean or non-grounded ice as is the case for fjords and cross-shelf troughs on formerly glaciated continental shelves.

\subsection{Remaining issues}

Despite the approaches that have been developed to interpolate channels in DEMs, there are a number of recurring problems in applying these methods in the next generation of the Greenland DEM. In particular, all of the methods assume that there are at least some data from which to extend and predict the structure of a given feature. Furthermore, no method is explicitly designed to include or represent the known physical characteristics, in particular the cross-sectional geometry, of the particular type of channel system (e.g. u-shape of glacial; v-shape of fluvial), with morphological information only being extended from available observations. Thus, there remains a disconnect between the presented frameworks and cases where features (1) are known to exist; (2) are assumed to conform to a structure related to the processes by which they were created (e.g. an assumed u-shape in the case of fjords where no other data are available); and (3) have no observations available to provide geometric constraints. A framework for fjord channel systems which addresses these issues, and can be applied to a large area such as the Greenland coast, must be able to
- impose morphological geometry to features of known process origin;

- account for elevation trends along and across the channel;

- account for confluences in dendritic channel systems;

- enable repeatable application across numerous channels within dendritic systems;

- deal with minimal data input (other than absolute limits, e.g. minimum and maximum depths as well as spatial extent).

\subsection{Stochastic models}

Stochastic models of bathymetry have long been employed to abyssal-hill features in the deep ocean (e.g. Goff and Jordan, 1988). In such places, stochastic models are appropriate for use because the frequency power spectra of deepocean bathymetry follow well-defined parametric relationships (Bell, 1975). Specifically, the high-frequency tail of the power spectra is characterised by power law relationships (i.e. the Brownian regime, which can be stochastically modelled), with lower-frequency behaviour characterised by a flat region of the power spectrum (i.e. the white regime, which cannot be stochastically modelled) (Goff and Jordan, 1988). This spectral behaviour is common across other types of natural terrain, and consequently spectral analysis of natural terrain often focuses upon establishing the transition between high- and low-frequency behaviour, and the characterisation of the high-frequency power law relationships (Shepard et al., 2001). Whilst the spectral properties of mid-ocean bathymetry (Bell, 1975; Goff and Jordan, 1988) and subglacial channels (Goff et al., 2014) have been assessed, to the best of our knowledge this has not been done for fjord bathymetry. As part of this study, we use data that are available from surveyed fjords to constrain the stochastic models of the bathymetry of many Greenland fjords.

\section{Methods}

A flow diagram for the separate components of our method for generating geomorphologically realistic fjord bathymetry is presented in Fig. 2. Each component is described in a separate sub-section. In Sect. 3.1 we discuss the approach taken to map the centreline of each fjord within the fjord system introduced below. Using the mapped centreline, we explain in Sect. 3.2 how a point mesh is developed, populating a given fjord with points extending from the centreline to the fjord edges based on the Greenland Ice Mapping Project (GIMP) land classification mask developed from remote-sensing imagery (Howat et al., 2014; Morlighem et al., 2014). Elevations are then associated with the points within the mesh, incorporating an assumed parabolic cross-profile geometry, 


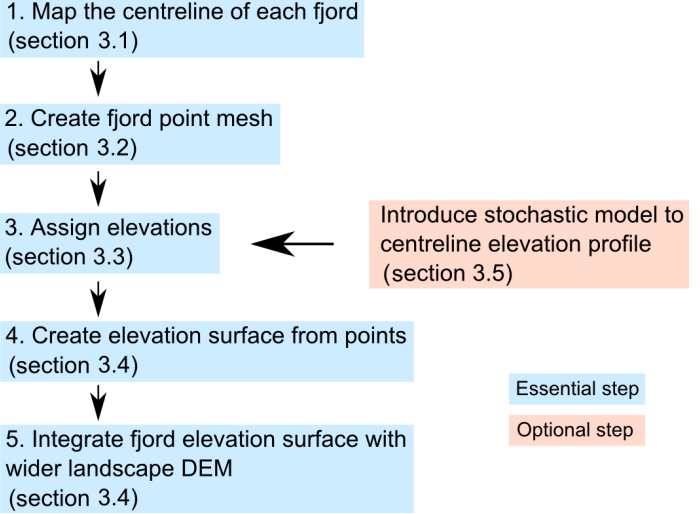

Figure 2. Algorithm flow diagram.

described in Sect. 3.3. The elevation dataset now developed is then used to create a continuous surface, representing the fjord bathymetry in Sect. 3.4. Finally in Sect. 3.5 we describe a stochastic modelling approach based on recently acquired observational data (Rignot et al., 2016; OMG Mission, 2016), the data being referred to as OBS1516 from this point forwards. The synthetic realisations within this study are based on two datasets - IBCAO and OBS1516. Consequently, we differentiate these simulations by naming them SynthIBCAO and SynthOBS respectively.

The sequential approach defined in Fig. 2 was applied to a fjord system in north-west Greenland close to Cape York (see Fig. 3) for which we identified and mapped the centrelines of five individual fjords. This fjord system was recently surveyed (OBS1516), as a result of which a DEM is now available and allows for a comparison between our synthetic generation method and in situ, high-resolution $(150 \mathrm{~m})$ gridded observations.

\subsection{Centreline mapping}

The ability to map a given fjord where no observations are available requires the provision of a skeleton mesh, which hinges on the presence of a centreline - an imaginary line that is equidistant from the two fjord edges. Consequently, the first step in the synthesis of a given fjord's geometry requires a centreline to be defined. Approaches exist for automatic centreline identification for glacier surfaces (e.g. Kienholz et al., 2014; James and Carrivick, 2016) as a means of avoiding manual digitisation. Such applications are, however, informed by the availability of a glacier surface elevation DEM. An equivalent non-geomorphologically based method includes the definition of the medial axis (cf. Blum, 1967) or topological skeleton and is frequently used in image processing and computer graphics applications (see Bai et al., 2007). Various packages are available to calculate topological skeletons (e.g. Van Der Walt et al., 2014). However, these algorithms are based purely on an input image and are sensitive to image pixel resolution. For our intended application,
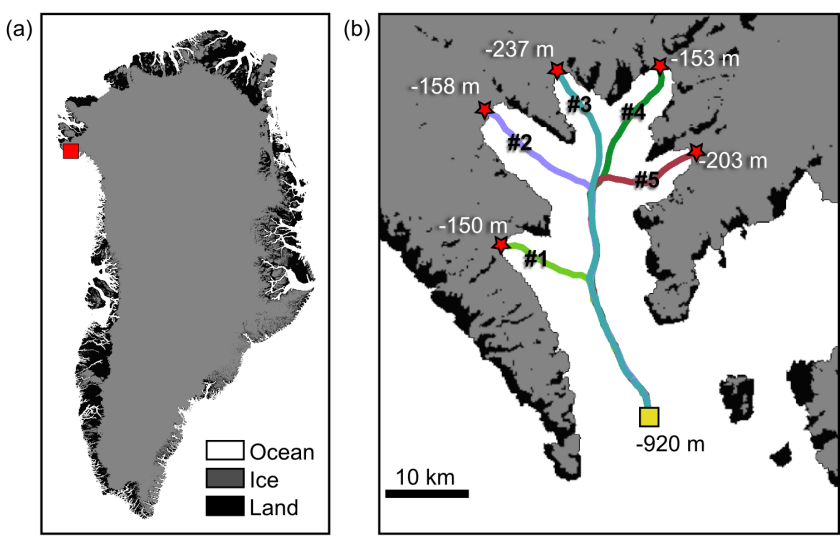

Figure 3. (a) The Cape York area of interest in north-west Greenland (red box - zoom displayed in $\mathbf{b}$ ) relative to the Greenland land classification mask (Morlighem et al., 2014). (b) The fjord system area of interest with mapped channel centrelines and seed (red star) and mouth (yellow square) elevations as identified from observations (OMG Mission, 2016).

this can result in the development of a centreline (or skeleton) with multiple branches along a single channel feature.

The centreline mapping method that we introduce allows fjord systems with multiple branches to be accounted for. Each centreline extends from a predefined seed point (or points) at the head of the fjord, ending at a predefined end zone (e.g. the fjord mouth). The centreline itself is defined by a series of points or vertices, each with a unique identifier. Fjord confluences and the implementation of network structure are described in Sect. 3.4. We define the centreline as being any path between a seed and the end zone which minimises the path length whilst maximising the distance of the path from the fjord walls. This removes the issues of multiple side branches that arise using existing skeletonisation approaches. The algorithm incorporates direction and thus an aspect of evolutionary landscape process knowledge, which ensures that the centreline captures a leading-order feature from the landscape it represents. Furthermore, this approach ensures that the paths and vertices are given unique identifiers enabling them to be specifically referenced, which is important when defining the channel mesh (see Sect. 3.2).

The generation of centrelines would be straightforward if we knew in advance the start and end points for each. In that case, we would simply compute a path that minimises the line integral

$J=\int_{C} L(x, y) \mathrm{d} c$,

where $C$ is the entire centreline and $L$ is some function that grows towards the channel edge. However, there are a large set of potential start points for every centreline, because we do not know ahead of time where any given channel should start. There are also a large set of potential end points, for the 

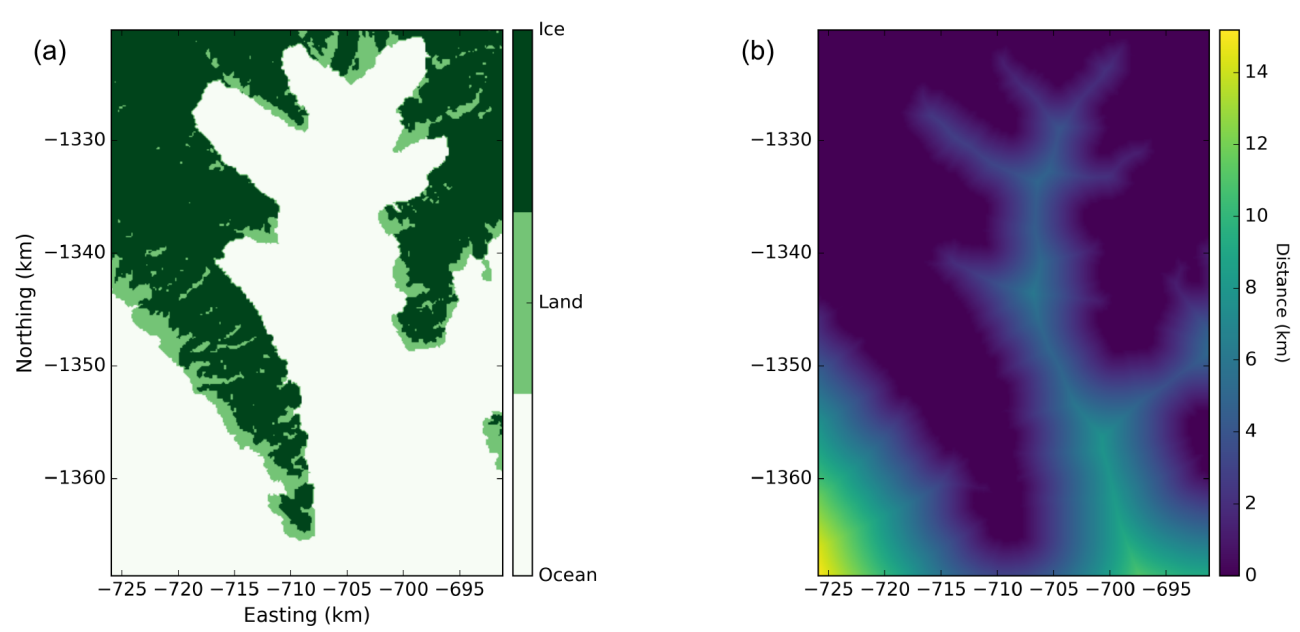

Figure 4. The area of interest close to Cape York illustrating (a) land classification taken from the GIMP land mask (Howat et al., 2014; Morlighem et al., 2014) and (b) the distance of ocean regions relative to land/ice regions.

same reason and also because there may be more than one centreline originating at any given start point if the channel is forked.

Fjords were identified as channels between areas of land and ice leading towards the open ocean, identified here using the modified GIMP land classification product (Howat et al., 2014; Morlighem et al., 2014) (see Fig. 3a). At the head of each fjord, multiple seeds were manually created from which to initiate a path. The end target was defined as a broad region rather than a specific point (in this case, the edge of the land classification mask). The following algorithmic steps were then undertaken:

1. Using the land classification mask, we calculate the distance of all locations between land/ice and ocean within the channel $(d)$, from which the shortest distance of any location within the ocean from regions of land or ice can be identified (see Fig. 4).

2. Based on the slope of the distance transform calculated for regions of ocean relative to land/ice land categories using GIMP (e.g. Fig. 4a), and considering the edges of the fjord, the initial seed points generate new points at a finite segment length $\Delta l$, chosen to resolve the path with sufficient detail (see Fig. 5a for a straight-fjord example and Fig. 5b for a curved fjord). Up to four new nodes are generated at each step, such that the angle between the newly defined segment and the parent segment is less than $\Delta l / r_{\mathrm{C}}$, the angle between any pair of new segments is no less than $\Delta a$ and the new segment does not cross the fjord boundary. $r_{\mathrm{C}}$ is chosen so that the minimum radius of curvature of any portion of the path is comparable to a typical channel width. The finite angle difference, $\Delta a$, like $\Delta l$, is chosen to be small enough to describe the channels adequately. See Table 1 for the values used. If we knew that no path would branch, we could generate a single new node; this more complicated procedure is adopted because we do need to consider branches. If more than four nodes are generated in this manner, then those with the smallest values of $L=1 / d^{4}$ (distance from the fjord edges) are selected.

3. Where, for example, a seed generates three new points, this results in the creation of three paths. Paths then increase in length as more points are created, with new paths following the creation of each new point. In the example illustrated in Fig. 5a, the initial seed creates three new points, each along a separate branch: 1.1, 2.1 and 3.1, each of which spawned its own new points and resultant branches, i.e. 1.1.1, 1.1.2 etc.

4. The process in step 3 alone would lead to exponential growth in the number of paths. To avoid this, paths are culled frequently (every three generations). Each path is categorised into bins $\left(x_{i}, y_{j}, a_{k}\right)$, where the centroid of the path $x, y$ satisfies $\left|x-x_{i}\right|,\left|y-y_{j}\right|<l_{\text {bin }}$, and the angle defined by the last edge added to the path, $a$, satisfies $\left|a-a_{k}\right|<a_{\text {bin }}$. The path with the lowest value for the path integral of $L$ is retained from each bin, and the remainder discarded. $l_{\text {bin }}$ is chosen so that the number of paths originating from seeds at the head of the same fjord are reduced to one in a few generations. $a_{\text {bin }}$ is chosen so that branches originating from the same start point persist long enough to have distinct centroids if they follow genuine branches in the channel. See Table 1 for the values used.

5. Where a path meets a boundary that is not the predefined end zone (e.g. land), the path is culled, as illustrated for branches 2.1.1 and 2.1.2 in Fig. 5a within the pink box. In this example, as a consequence of the boundary inter- 
Table 1. Parameters and values in the centreline mapping algorithm as applied to the area of interest presented in Fig. 3

\begin{tabular}{llr}
\hline Parameter & Description & Value \\
\hline$\Delta l$ & Finite path segment length & $0.8 \mathrm{~km}$ \\
$r_{\mathrm{C}}$ & Minimum radius of curvature & $6 \Delta l / \pi$ \\
$\Delta a$ & Finite path angle difference & $\pi / 24$ \\
$l_{\text {bin }}$ & Bin spatial extent & $16 \mathrm{~km}$ \\
$a_{\text {bin }}$ & Bin angle extent & $\pi / 8$ \\
\hline
\end{tabular}

cept, there is a resultant culling of both paths 2.1.1 and 2.1.2, following the removal of the parent node 2.1.

6. Once a given path reaches the target region, its length is compared to the length of all other complete paths, with only the shortest being retained. In Fig. 5a, paths 1.8.1, 1.8.2 and 1.8.3 complete, the shortest where $L$ is minimised (1.8.2) being retained and used to define the fjord centreline.

7. A centre of mass $(\mathrm{COM})$ is calculated for each path. Where the distance between the COM of separate paths is greater than a threshold value (manually set to $\sim$ half of the mean channel width in an area), both paths are kept regardless of length; otherwise the shorter, where $L$ is minimised, of the two paths is retained. The use of the COM allows for separate centrelines to be defined along more complex fjord networks than by culling according to path length alone.

\subsection{Fjord mesh development}

For each fjord centreline, points normal to each centreline vertex were defined up to the fjord edge taken from the GIMP land mask (Fig. 6). The angle of the normal vector along which these new points were defined was calculated from its orthogonal relationship with the vector joining the neighbours of a given centreline vertex. To avoid an irregular distribution of new points in the interpolated profile at the channel edges, the points used to define the vector from which the normal was calculated were sometimes selected from more distant neighbours. This was particularly pertinent at more sinuous sections of a centreline. This smoothing of the profile is adapted from Goff and Nordfjord (2004). Vertices normal to the centreline were calculated up to the mouth of the channel, at which point the fjord centreline was manually clipped.

\subsection{Mesh elevation definition and cross-sectional fjord geometry}

Elevations were attributed to the point mesh by first constraining the seed and fjord-edge bed elevations through association with the nearest bedrock/bathymetric observation (from ice-penetrating radar where ice-covered (see Bam- (a)

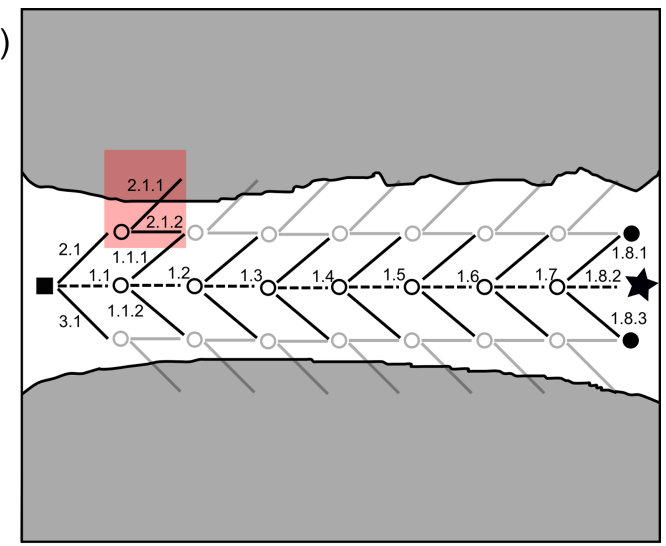

(b)

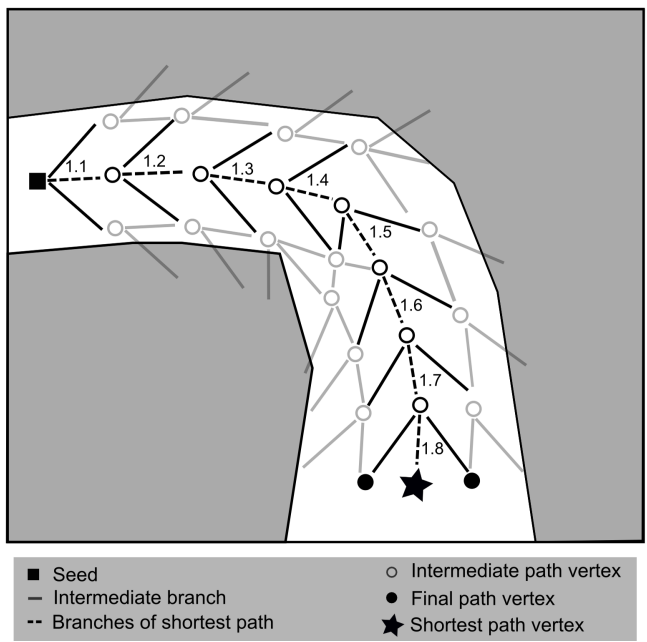

Figure 5. Generalisation of the fjord centreline approach where the centreline pathfinder algorithm is applied to a (a) straight ford and (b) a curved fjord. Grey regions represent land and ice, with white regions representing the fjord. From a seed point, new points are spawned, each time resulting in the creation of new branches. Where points intersect the land-ice boundary, branches are culled. The culling of branches 2.1.1 and 2.1.2 within the pink box in (a) and the selection of the shortest path are discussed in the text.

ber et al., 2013); from altimetry where bedrock was exposed (Howat et al., 2014); or from bathymetric observations, OBS1516). This method ensured that at the head of the fjord three elevations were available - the two edges of the fjords (taken as the elevations at the first land locations encountered at the fjord edges) and a centreline elevation. For future applications along the Greenland coast where seed data are sparse, modelled estimates from the mass conservation optimisation scheme (Morlighem et al., 2014) could be used.

Two approaches were taken to assign bed elevation values along the centreline of a given fjord. In both approaches, bed elevations were linearly interpolated between a known bed elevation at the head of the fjord (taken from OBS1516, Fig. 3b) and a known bed elevation at the mouth of the fjord - the mouth having been manually located and consistently 


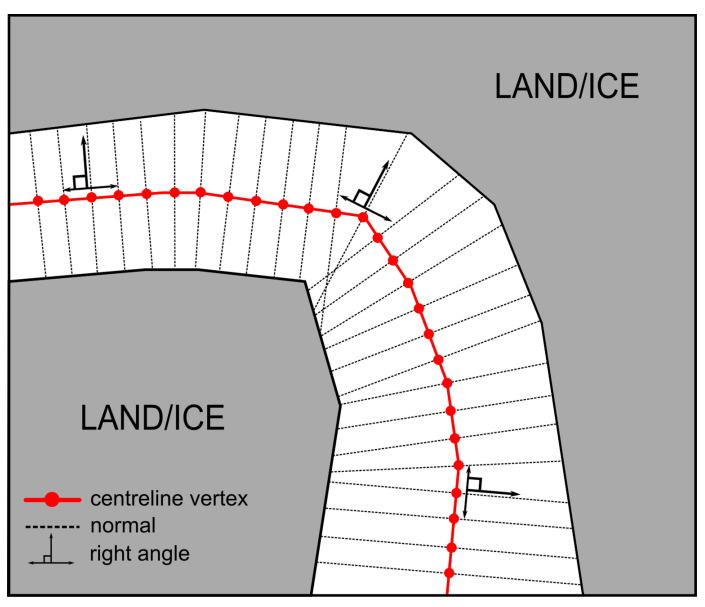

Figure 6. For a given centreline vertex, new points (black dashed lines) are created normal to the centreline trajectory (solid red line), up to the sides of the channel as defined by the land-ocean mask (Howat et al., 2014; Morlighem et al., 2014). Normal angles are calculated relative to the vector between the neighbouring points of a given vertex.

used for all model runs. For the first run (SynthIBCAO), the bed elevation at the mouth was taken from the nearest IBCAO observation $(20 \mathrm{~km}$ from the mouth of the fjord system depicted in Fig. 3) and was set at $-803 \mathrm{~m}$. This was chosen for the first simulation as until recently IBCAO provided the most extensive bathymetric dataset for Greenland, and the distance from a fjord head to the nearest observation is often $\sim 10 \mathrm{~s}$ of kilometres. For the second run (SynthOBS), the gridded bathymetric observation from OBS1516 at the same position was used ( $-920 \mathrm{~m}$; see Fig. 3b). Should highfrequency stochastic perturbations wish to be added along the profile (see Sects. 3.5 and 4.5), they would be applied at this stage. Bed elevations up to the termini of most glaciers in Greenland, albeit predominantly modelled, are now available (Morlighem et al., 2014). We justify the use of the OBS1516 data for defining the elevations at the head of each fjord in the presented simulations as it enables a comparison of synthetic and observational data directly, removing the need to consider uncertainties inherent of modelled elevations.

In the absence of large-scale studies on fjord bathymetric geometry, we base our cross-sectional fjord geometry on the prior analysis of over 8000 glacially eroded valleys now exposed by interglacial ice sheet retreat (Coles, 2014). In their study, profiles were acquired from different glacial and geological environments, including valleys from the Southern Alps (New Zealand), the Pyrenees, and north and south Patagonia. For the valleys the elevation, $V_{d}$, was fitted to a power law relationship for the form

$V_{d}=\alpha|w|^{\beta}$,

where $\alpha$ is the form ratio (valley depth/valley top width), $w$ is the distance along the cross section from the centreline (the position of which corresponds to $w=0$ ) and $\beta$ is the power law exponent. Best fit parameters of $\alpha=0.20$ and $\beta=$ 1.38 were obtained (Coles, 2014). A value of $\beta=2$ (i.e. a parabolic relation) follows Wheeler (1984).

Equation (2) assumes that a given fjord's cross section is symmetrical about the centreline, with the centreline as the deepest point - an assumption which usually does not hold exactly. Additionally, the fjords are often seeded with edge elevation data that are significantly higher on one side of the fjord than the other. To define the cross-sectional fjord geometry, we define a parabola of the form $a x^{2}+b x+c$ (Wheeler, 1984), where $a, b$ and $c$ are calculated based on the known elevations and relative locations of the edge and centreline points. This enables us to relax the constraint that the centreline must be the deepest point. Thus, the parabola used to define across-fjord geometry in this study is inspired by the analyses of Coles (2014) but not a direct application of it.

\subsection{Fjord surface generation, implementation of fjord confluences and wider integration with DEMs}

Following the development of a complete fjord elevation mesh, a surface was then made for each fjord, with mesh point elevations being mapped to a regular grid, thus creating a continuous surface. The resultant grid was then masked using the GIMP mask, thus removing any values outside the extent of the point mesh which arose as a result of the regular gridding process. The individual fjord grids were then combined, from which a final grid of the minimum values (or maximum depths) was created. Thus, the lowest value at any location where two fjords overlap was retained (Goff and Nordfjord, 2004). As a result, deeper grid values took precedence over those that were shallower. This approach coupled with the aforementioned setting of edge elevations at confluence locations avoids the creation of ridge artefacts in the final DEM. The fjord DEM was then integrated into the wider landscape DEM (Bed2013), which includes non-fjord regions. Prior to the merge, Bed2013 was masked, removing any values in the area occupied by the synthetic fjord(s).

\subsection{Stochastic modelling of fjord bathymetry}

In this section we describe spectral analysis methods used to constrain the fjord's statistical features and the inverse methods that can be used to generate a synthetic profile. Our analysis is based upon analogous analysis of abyssal-hill features in the mid-ocean (Bell, 1975; Goff and Jordan, 1988), although it is simpler in the respect that fjord bathymetry is approximated as a one-dimensional problem. Using the centreline mapping approach presented in Sect. 3.1, centreline points were established, with vertices on a $150 \mathrm{~m}$ interval for nine fjords along the west Greenland coast, selected where mean gridded observations were contiguous along fjord centrelines according to OBS1516 (Fig. 7). 

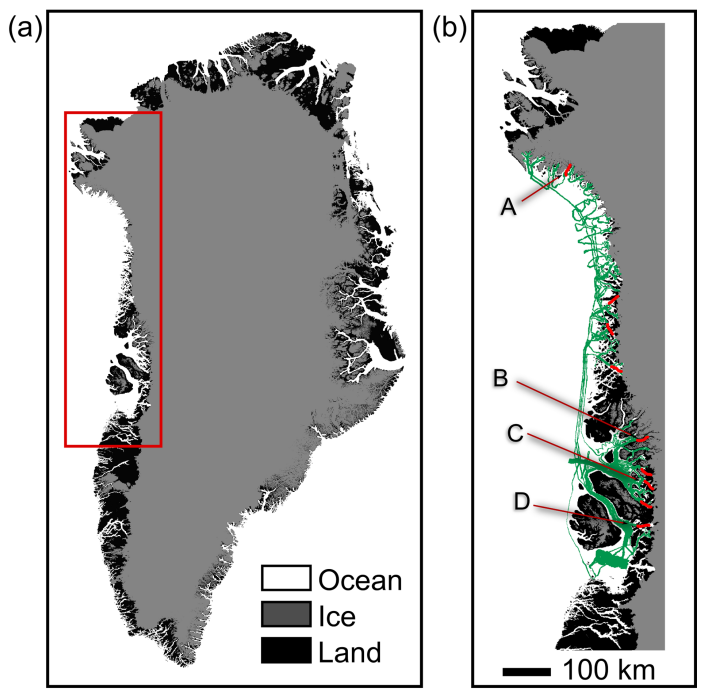

Figure 7. (a) Area of interest considered for selection of fjord centrelines for spectral analysis relative to the GIMP land classification mask (Morlighem et al., 2014). (b) Fjord centrelines (red) selected along the west coast of Greenland, with the bathymetric observational DEM also displayed (green) (Rignot et al., 2016, OMG Mission, 2016) - centrelines were only selected where data were available, with gaps affecting $<20 \%$ of the overall profile length. Labels on (b) relate to the profiles illustrated in Fig. 8.

The lengths of the nine fjord sections in our example are constrained by the length of the shortest fjord section $(\sim 30 \mathrm{~km})$. Elevations were extracted for each centreline vertex, providing one-dimensional centreline elevation profiles. Where a centreline contained missing data at a level no greater than $20 \%$, a cubic interpolation routine was applied to give a continuous elevation profile (Fig. 8). Prior to performing the spectral analysis, each elevation profile was linearly detrended, which acts to emphasise the overall variation of the small-scale trends (Shepard et al., 2001). Each elevation profile was then transformed using the numerical fast Fourier transform algorithm, converting it to the frequency domain (Van Der Walt et al., 2011). Power spectra for each fjord were then obtained from the square of the complex modulus, and arithmetically averaged over the nine selected fjord profiles, to create a composite power spectra. This arithmetic averaging approach is as described in Bell (1975) for mid-ocean bathymetry and enables longer wavelength features to be statistically constrained along with the higher-frequency features that are repeatedly sampled.

Of interest in this study is demonstrating, in a proof-ofconcept manner, how the composite power spectra for the fjords can be used to generate different one-dimensional realisations of synthetic bathymetry that are consistent with the overall statistical properties. In order to generate the different realisations of bathymetry, we use the inverse Fourier transform method outlined by Tyan et al. (2009) (the sinusoidal approximation method described in Sect. 4 of their study).
Their method was introduced in the context of generating one-dimensional random road profiles, which is a mathematical analogue of fjord profiles. In their formulation the Fourier amplitudes of each harmonic are determined by the power spectra of the profile, with stochasticity present via the random relative phase of each harmonic. Our only modification to their method is to use a different parametric form for the power spectra, which is motivated by our observed results described in Sect. 4.5 and is consistent with the generality of their method.

\section{Results}

In this section, we present differences between Bed2013 (the last Greenland bed-bathymetry combined data product following Bamber et al., 2013), OBS1516 (recently acquired fjord bathymetry data) and synthetic fjord bathymetry developed using the methods described in Sects. 3.1-3.4. The first synthetic application is preconditioned using the nearest IBCAO bathymetric observations (SynthIBCAO), and the latter using the OBS1516 dataset (SynthOBS). The results are compared to Bed2013 and OBS1516, in the region illustrated in Fig. 3. Selected fjord profiles sampled from available bathymetry data in the region illustrated in Fig. 7 are presented in Fig. 8 following application of the method described in Sect. 3.5.

\subsection{Bed elevation differences for OBS1516 vs. Bed2013}

We consider areas of maximum over- and underestimation of bed elevation that are present in Bed2013 within the region covered by OBS1516. Bed2013 is a continuous DEM extending from the bed beneath the contemporary ice sheet out to the continental shelf in the ocean, with all bathymetric information derived from IBCAO. IBCAO was combined with the bed elevation component of Bed2013, with triangulation used as an interpolator to provide values where IBCAO was unconstrained by data (Bamber et al., 2013). Triangulated portions of the resultant DEM were then smoothed using a $2 \mathrm{~km}$ window (Bamber et al., 2013). Where there was an unrealistic offset between the two surface datasets (e.g. bathymetry was higher than the glacier bed), some areas were manually dropped to force them to adhere to a subjectively more realistic profile (i.e. a fjord would be lower than the glacier bed upstream of it). The result of differencing Bed2013 from the OBS1516 dataset is presented in Fig. 9a, relative to Greenland (Fig. 9b), with the frequency distribution of the differences presented in Fig. 9c. On average, Bed2013 underestimated the depth of OBS1516 by $115 \mathrm{~m}$, for which a skewness of -0.7 from the difference frequency density distribution was identified. These overall dataset statistics obscure the regions of maximum depth underestimation which are focused within the fjords themselves. Absolute maximum under- and overestimates of OBS1516 by 

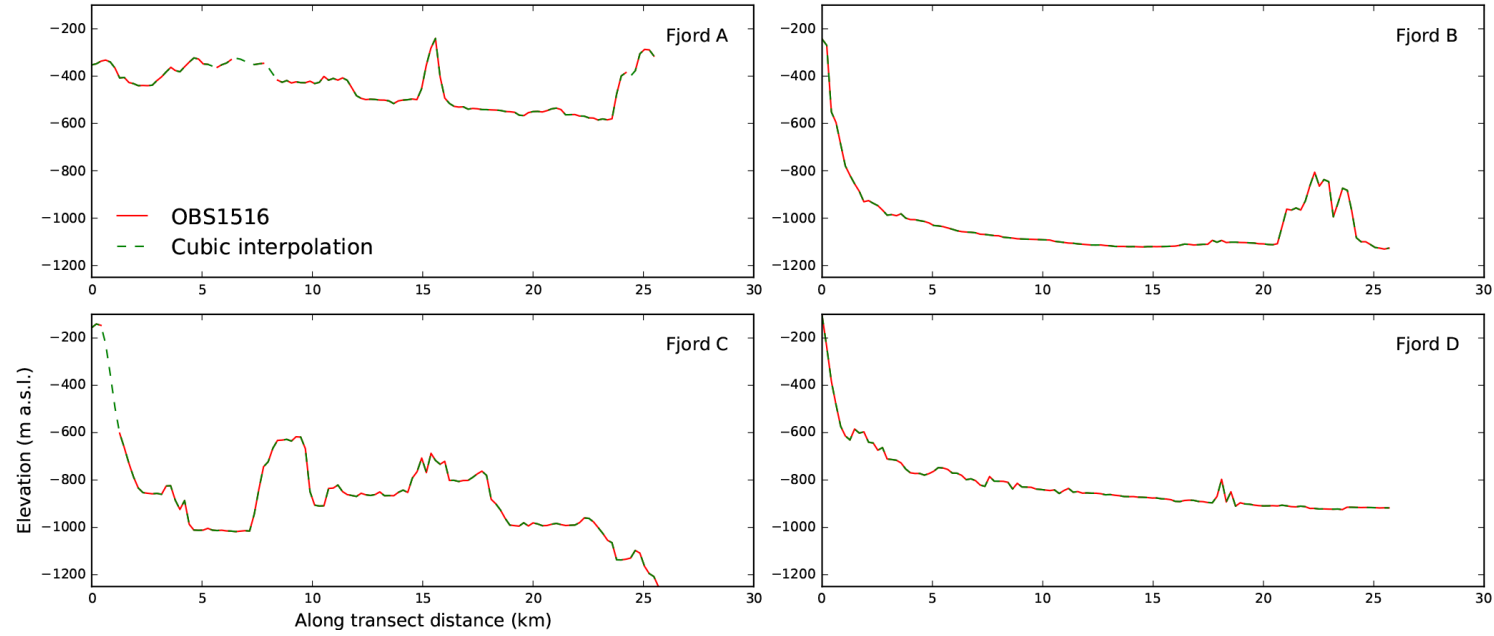

Figure 8. Examples of the along-transect profile of four fjords from the area of interest depicted and labelled in Fig. 7a and $b$ respectively. Along-transect distance starts at the head of each fjord and extends to the fjord mouth.

(a)

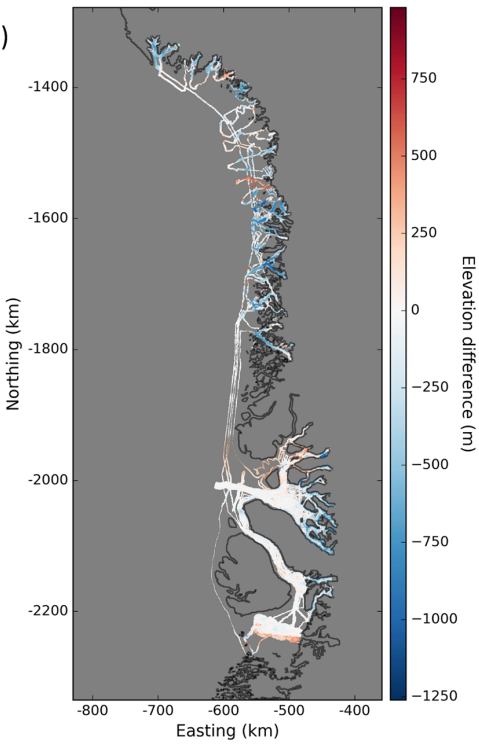

(b)
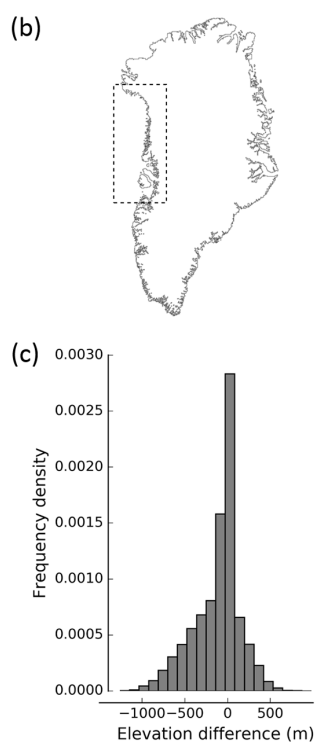

Figure 9. Bed elevation differences (OBS1516 minus Bed2013) (a) at all surveyed locations along the west Greenland coast (b) and as a frequency distribution (c). Red regions in (a) indicate bathymetry elevation overestimation by Bed2013 (too deep), with blue regions illustrating underestimation (Bed2013 too shallow).

Bed2013 reached -1329 and $1077 \mathrm{~m}$ respectively. Regions containing these extreme values can be directly associated with portions of the IBCAO dataset that were unconstrained by observations and were themselves the result of triangulation (Bamber et al., 2013) and spline interpolation (Jakobsson et al., 2012).

\subsection{Bathymetry for SynthIBCAO}

The first implementation of the synthetic fjord routine, SynthIBCAO, defines the elevation at the mouth of the fjord based on the nearest IBCAO bathymetric observation, with the elevation of the point at the head of the fjord taken from the OBS1516 dataset (Fig. 10a). Points normal to each centreline vertex were then calculated as described in Sects. 3.2 and 3.3. The resultant combined surface DEM with the inclusion of synthetically created fjord bathymetry, providing a new realisation of the bathymetry as in Bed2013 (Fig. 10b), is displayed in Fig. 10c.

The SynthIBCAO channel geometry is both deeper and more concave than Bed2013 (Fig. 10b), particularly with regard to the narrower fjord regions. Based on the contour pattern (Fig. 10c), these narrower fjord regions now display a deeper and more concave cross-sectional profile than was rendered in Bed2013. For the wider confluence region centred south from $(-705,-1340)$ in Fig. 10c, there is a clear change in the overall depth profile, with SynthIBCAO reaching $-731 \mathrm{~m}$ compared to $-391 \mathrm{~m}$ in Bed2013. SynthIBCAO reaches a minimum bed elevation different to the defined elevation at the mouth of the fjord $(-803 \mathrm{~m})$ as a result of the regular gridding of the fjord mesh elevations described in Sect. 3.4.

Comparing the difference between Bed2013 and SynthIBCAO (Fig. 11a), the latter dataset has elevations consistently lower than the former. The mean offset between the two datasets was $274 \mathrm{~m}$. The changes along the narrower portions of the fjords - up to $\sim 3 \mathrm{~km}$ from each respective fjord head (see Fig. 3b for mapped channel centrelines) - are relatively small $(\sim 0-50 \mathrm{~m})$. Larger offsets are apparent where fjords enter the confluence region centred south from $(-705$, -1340 ) in Fig. 11a, with a maximum offset of $547 \mathrm{~m}$. The increased concavity of SynthIBCAO is well illustrated with a 

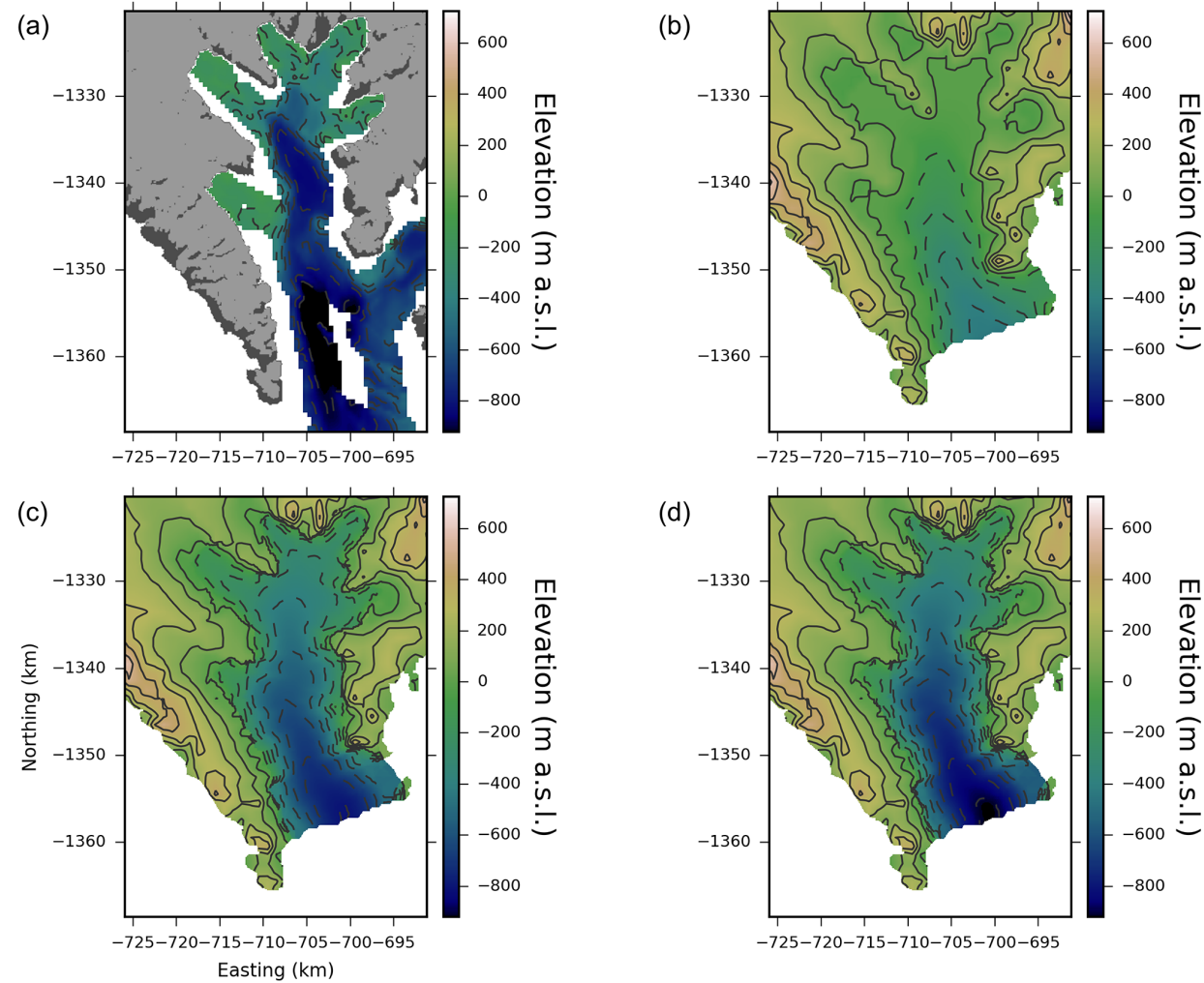

Figure 10. The area of interest close to Cape York displaying (a) the land mask of the area of interest (Morlighem et al., 2014) with ice (light grey), ice-free land (dark grey) and ocean (white) along with the OBS1516 elevations; (b) Bed2013 elevation; (c) Bed2013 combined with the SynthIBCAO synthetic geometry; and (d) Bed2013 with the inclusion of the SynthOBS synthetic geometry. SynthIBCAO and SynthOBS are only used within the ocean regions of the land mask.

mean increase in depth along the confluence zone centreline of $\sim 370 \mathrm{~m}$.

Subtracting SynthIBCAO from OBS1516 (Fig. 11b) reveals a mean offset between the two datasets of around $50 \mathrm{~m}$. Relatively good agreement along the first $\sim 3 \mathrm{~km}$ of each fjord (see Fig. 3b for mapped channel centrelines) is displayed, and indeed portions of the main confluence region, with differences centred at $0 \mathrm{~m}$. The main region of synthetic elevation overestimation (i.e. lower than the observations) is focused at the confluence point of fjord 1 (refer back to Fig. $3 \mathrm{~b}$ for fjord numbers), with the region of overestimation focused around $(-709,-1344)$ in Fig. $11 \mathrm{~b}$ up to a value of $\sim 580 \mathrm{~m}$. This overestimate is likely indicative of the presence of a sill-like feature in OBS1516. The two main regions of depth underestimation using SynthIBCAO are centred at $(-704,-1338)$ and $(-704,-1355)$ in Fig. 11b, with maximum underestimates of $\sim 385$ and $\sim 358 \mathrm{~m}$ respectively. These underestimates possibly relate to the presence of overdeepening type features present in OBS1516.

For reference, a comparison with OBS1516 subtracted from Bed2013 for the same area of interest is drawn (Fig. 11e). As described in Sect. 4.1, Bed2013 consistently underestimates bed elevation. However, as with SynthIB$\mathrm{CAO}$, the main areas of underestimation are focused at the same locations - namely $(704,-1338)$ and $(-704,-1355)$ in Fig. 11e for which overdeepenings are likely present.

\subsection{Bathymetry for SynthOBS}

The second implementation of the synthetic fjord routine, SynthOBS, defines the elevation of points at both the head and mouth of the fjord based on gridded elevations from OBS1516 at the same location. The resultant combined surface DEM with the inclusion of synthetically created fjord bathymetry is displayed in Fig. 10d. SynthOBS demonstrates deeper concave geometry across the fjords than Bed2013. The changing relief of the banks of the synthetic fjords are steeper than those rendered in the original DEM (Fig. 10b). Between fjords, there are also changes in the elevations of the ridges such as at $(-706,-1330)$ in Fig. 10d. The differences between the synthetic and the original DEMs are further quantified by the difference plot illustrated in Fig. 11c.

The SynthOBS surface is generally lower than Bed2013 (Fig. 11c), with a mean offset between the two datasets of $316 \mathrm{~m}$. The only locations where SynthOBS was higher than Bed2013 were at the edges of the fjords within $\sim 3 \mathrm{~km}$ from each respective fjord head (see Fig. 3b for mapped channel centrelines). This possibly highlights overly smoothed sec- 

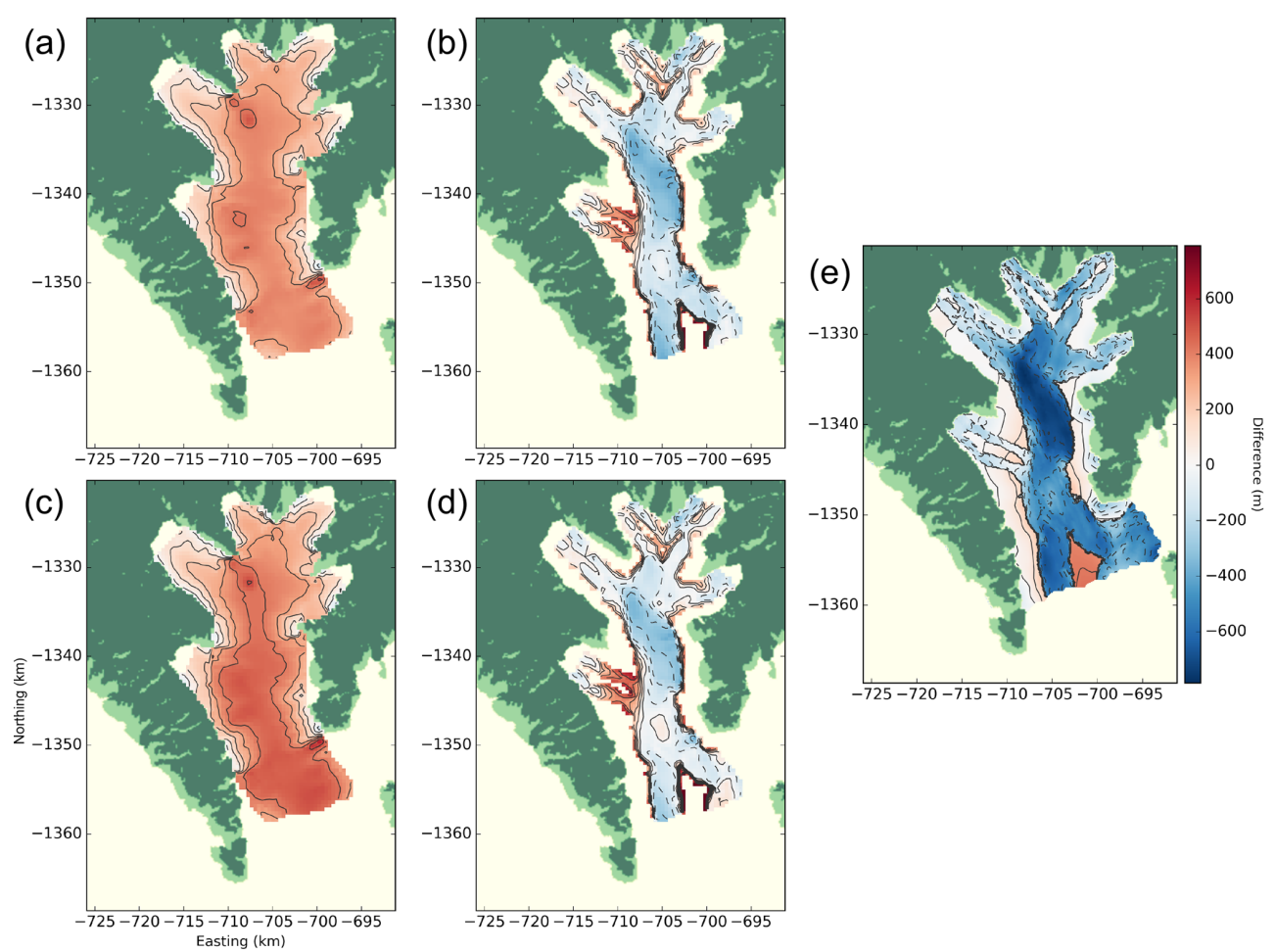

Figure 11. Bed elevation differences displaying (a) Bed2013 minus SynthIBCAO, (b) OBS1516 minus SynthIBCAO, (c) Bed2013 minus SynthOBS, (d) OBS1516 minus SynthOBS and (e) OBS1516 minus Bed2013 within the Cape York area of interest. Positive differences (red) occur where the subtrahend is deeper than the minuend, with negative differences (blue) occurring where the subtrahend is shallower than the minuend.

tions of Bed2013 (where it was combined with the IBCAO dataset - see Bamber et al., 2013). As with the SynthIB$\mathrm{CAO}$ approach, the largest offsets are apparent as fjords enter the confluence region centred south from $(-705,-1340)$ in Fig. 11c, with a mean offset in this region of $\sim 400 \mathrm{~m}$.

When SynthOBS is subtracted from OBS1516 (Fig. 11d), the mean offset between the two datasets is $\sim-3 \mathrm{~m}$. The spatial pattern is very similar to that described for SynthIBCAO, with the same regions of under- and overestimation being equally apparent. Specific values, however, differ. Maximum synthetic elevation overestimation focused around $(-709$, -1344 ) in Fig. 11d was $\sim 581 \mathrm{~m}$. The two main regions of synthetic elevation underestimation (i.e. higher than the observations) using SynthOBS centred at $(-704,-1338)$ and $(-704,-1355)$ in Fig. 11d have maximum underestimates of $\sim 328$ and $\sim 283 \mathrm{~m}$ respectively. Overall, the profile represented by SynthOBS is closer to OBS1516, as would be expected considering the elevation profile of each fjord was calculated between fjord head and mouth observations from the OBS1516 dataset.

\subsection{Centreline profile changes: Bed2013, OBS1516, SynthIBCAO and SynthOBS}

Considering centreline profiles for all fjords, we illustrate the improvements made to the general elevation profile of each fjord (Fig. 12) relative to those present in Bed2013, by considering the general agreement between the synthetic geometry and OBS1516. The synthetic realisations underestimate observed bathymetric elevation to a much lesser extent than Bed2013, capturing the generally sloping profile of OBS1516. The good agreement (approximately $\pm 50 \mathrm{~m}$ ) of synthetic-observed values along the first $\sim 3 \mathrm{~km}$ of each fjord - in particular for fjords 1,2 and 5-implies the presence of approximately linear profiles. Larger differences indicative of where the synthetic approach performs less well - occur from $\sim 4 \mathrm{~km}$ along each centreline, which relates to the confluence region of the individual fjords (refer to Fig. 3). Higher-frequency features (along-track peaks and troughs likely relating to sills and overdeepenings) are not captured using the presented synthetic fjord bathymetry generation approaches.

\subsection{Spectral characteristics of observed fjords}

Following Sect. 3.5, we now consider the spectral characteristics of the fjord bathymetry along the centrelines of the 

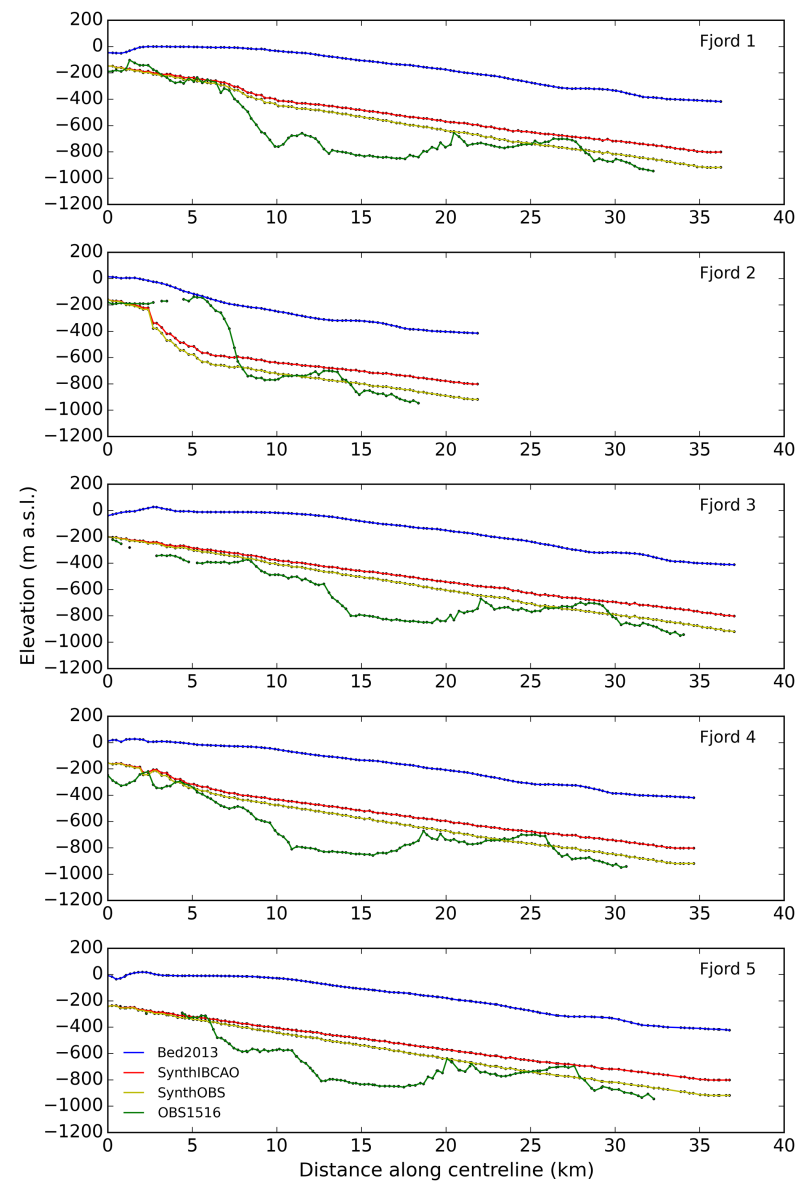

Figure 12. Centreline elevation profiles from Bed2013, OBS1516 and the SynthIBCAO and SynthOBS synthetic algorithm approaches. All profiles extend from the head of each fjord to the mouth as depicted in Fig. 3.

nine fjords illustrated earlier in Fig. 7b, using the OBS1516 data. A $\log -\log$ plot for the mean power spectra, $S(k)$, where $k$ is the wave number (linear spatial frequency), is presented in Fig. 13 (blue crosses). The power spectra exhibit an approximate power law relationship at higher frequencies (corresponding to a linear relationship in log-log space) and an approximate flattening at lower frequencies. A parametric model which captures this frequency transition is

$S(k)=\frac{F_{0}}{k^{\alpha}+k_{0}^{\alpha}}$,

where $k_{0}$ represents the approximate transition frequency between the high- and low-frequency regimes, $\alpha$ is the exponent for the high-frequency tail (for $k \gg k_{0}, S(k) \propto k^{-\alpha}$ ) and $F_{0}$ acts as a normalisation constant. The parametric model (Eq. 3) is a generalisation of the model for the power spectra of ocean bathymetry in Bell (1975), which assumes $\alpha=2$. In general, different types of natural terrain can exhibit a range of spectral exponents (Goff and Jordan, 1988; Shepard et al.,

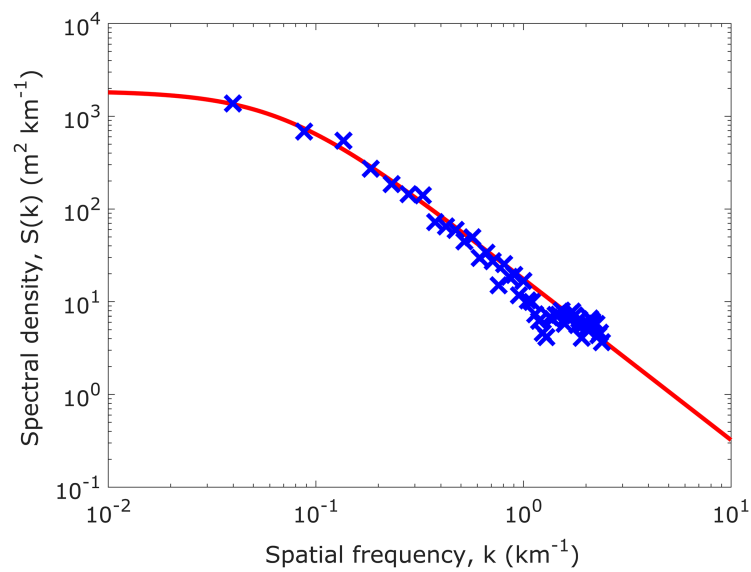

Figure 13. Composite power spectral density from fjord bed elevation profiles. Blue crosses indicate spectral data that have been averaged over nine fjord profiles, and the solid red curve is the best fit to the parametric model, Eq. (3).

1995, 2001), and our parametric model is representative of this.

The parametric best-fit values were obtained using a non-linear least-squares solver and correspond to $F_{0}=$ $17.6 \mathrm{~m}^{2} \mathrm{~km}^{-1}, k_{0}=0.069 \mathrm{~km}^{-1}$ and $\alpha=1.74$ (Fig. 13, red solid line). The transition frequency, $k_{0}=0.069 \mathrm{~km}^{-1}$, corresponds to a transition wavelength of $14.5 \mathrm{~km}$. This compares with a transition spatial frequency $k_{0}=0.025 \mathrm{~km}^{-1}$, and a transition wavelength of $40 \mathrm{~km}$, for abyssal-hill features in the mid-ocean in Bell (1975).

Figure 14 shows two different realisations of synthetic fjord bathymetry using the parametric fit to the power spectra in Fig. 13 and the stochastic inverse Fourier transform procedure described in Sect. 3.5. The horizontal spacing of the synthetically generated profiles is set to be the same as the bathymetric data $(0.2 \mathrm{~km})$. If we draw a comparison between the stochastic model of synthetic fjord centreline profiles and the OBS1516 profiles (Fig. 12), it is clear that the synthetic profiles do not contain the lowest-frequency oscillations (wavelengths $\sim 15 \mathrm{~km}$ or greater). This is consistent with the general flattening of the fjord power spectra at low frequencies. However, oscillations on a length scale $\sim 5 \mathrm{~km}$ (typical of sills and overdeepenings) are present in the synthetic profiles, although the specific locations of such features in these profiles are random.

\section{Discussion}

Channel elevation point meshes have been implemented in different research fields, including hydrology (Merwade et al., 2005, 2008) and glaciology (Goff et al., 2014). This study provides a key addition, which addresses sparse data availability with the introduction of parabolic cross-sectional form along each profile that is characteristic of glacial fjords. 


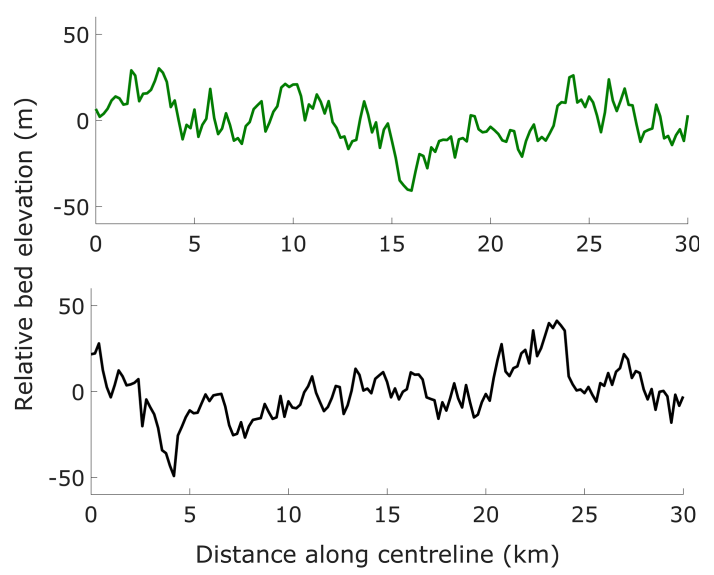

Figure 14. Two different realisations of the stochastic model for high-frequency perturbations to the synthetic fjord elevation profiles. The model uses the parametric fit in Fig. 13 to generate the profiles and is statistically consistent with the OBS1516 bathymetric profiles (green lines in Fig. 12). The overall trend of the fjord bathymetry and lower-frequency oscillations (corresponding to wavelengths $14 \mathrm{~km}$ or greater) is not synthetically generated and explains why the amplitude of the modelled elevation is significantly less than the bathymetric observations in Fig. 12.

In the absence of data, continuous DEM surfaces are developed using interpolation procedures. The specific values assigned to regions lacking observations are thus entirely dependent on the interpolation routine applied, and the presented approach provides a geomorphologically realistic estimate of elevations in these regions. The introduction of the artificial mesh removes the need to apply a traditional interpolation routine over a large region, instead providing an idealised mesh to constrain regions known to be fjords. The method presented must, however, be semi-informed by data. The minimum elevations that are required are the fjord bank edges (i.e. topographic elevation at the land-ocean interface according to a land mask, e.g. GIMP) - which in general can be different from one another - as well as the elevation of the assumed centreline. The deepest point along the channel is constrained by the quadratic fit. In the case of Greenland, for which this method has been developed, icefree edge observations are widely available (e.g. Howat et al., 2014; Korsgaard et al., 2016). Equally, observations at the head of the fjord can be taken from bed elevations inferred from mass conservation (Morlighem et al., 2014) or, in some regions, radar observations (e.g. Gogineni et al., 2001). Finally, observations for the fjord mouth could be taken from datasets including IBCAO or others (e.g. Schjøth et al., 2012; Dowdeswell et al., 2014; Arndt et al., 2015; Rignot et al., 2016); however these values may be at a significant distance from the fjord mouth itself, which using the presented approach may result in further under- or overestimation of a given fjord centreline elevation profile.
The synthetic approaches - SynthIBCAO and SynthOBS as presented in Sects. 4.2 and 4.3 respectively - represent two situations that would be encountered when applying the method, as part of wider Greenland DEM development, to fjords around Greenland. By informing the mouth elevation on IBCAO observational data at a distance of $\sim 20 \mathrm{~km}$ from the mouth, the impact of using distant bathymetric observation is exemplified. Equally, as many fjords have at least some information following various recent campaigns (including Schjøth et al., 2012; Dowdeswell et al., 2014; Arndt et al., 2015; Rignot et al., 2016), the use of observational data to constrain the algorithm is illustrated by SynthOBS. The application of these two synthetic approaches has provided bathymetry more representative of the observed elevation profiles (OBS1516) of fjords within the area of interest (Fig. 12). Within this region, topographic features, such as sills and overdeepenings, captured within OBS1516 occur. It is not possible to predict oscillatory features such as those with the geometrically flat surfaces assumed by our basic algorithm. In these examples, the overdeepening features and sills have a length scale $\sim 5 \mathrm{~km}$, which is less than the transition wavelength for the fjord power spectrum of $\sim 15 \mathrm{~km}$ (Fig. 13). The transition wavelength provides an approximate upper bound upon the length scale of features which could be modelled using our stochastic framework. Consequently if we integrated the analysis here with the stochastic model, the overall statistics of the overdeepening features would be reasonably well represented, but their geographical locations would not.

With regard to confluences - and following Goff and Nordfjord (2004), where single channel elevation surfaces overlap - we accept the maximum depth. This introduces a hierarchical element to surface prediction, whereby deeper channels are favoured over shallower ones. However, as the approach is based solely on topography (not rock type or age as such information is rarely available), this introduces a limitation that cannot easily be resolved in light of such sparse observations. We suggest that, in the absence of data, use of the deepest value is preferable over shallower values, due to the overall systematic overestimation of bed elevation (i.e. underestimation of depth) by Bed2013 (see Sect. 4.1). The presence of overdeepenings within glacial environments is well established (c.f. Cook and Swift, 2012), their distribution having been observed from bed DEMs for beneath contemporary ice sheets including that of Greenland (Patton et al., 2016). However, there remain limited quantitative data on their morphology with which to understand the processes of their development (Patton et al., 2015) and the specific relationship between fjord network structure and the locations of overdeepenings and the sills between them. Should additional information become available, such an approach to establish their location could be implemented by introducing rules - for example, "an overdeepening of a given step lowering occurs where two fjords of a given width and known depth confluence". Another approach would be to develop a 
set of rules which incorporate a fjord hierarchy akin to stream order and their associated Strahler numbers (Strahler, 1957).

The majority of end users of a new Greenland bed DEM including improved bathymetry are expected to be within the ice sheet and polar ocean modelling communities. With this in mind, the approach presented here has been tailored to best suit the purpose of end products that have fjord bathymetry constrained by the synthetic algorithm. Since the algorithm performs better closer to the glacier termini, as opposed to the fjord mouth, users of DEM products based upon this algorithm would be encouraged to focus on processes from the glacier-to-fjord direction (e.g. calving) as opposed to processes focused from the fjord-to-glacier direction (e.g. ocean forcing as in Murray et al., 2010). The impact of high- and low-frequency stochastic perturbations for topographic datasets for ice sheet modelling is well documented, with models being more sensitive to spatially broad low-frequency noise as opposed to higher-frequency noise of the same magnitude (Sun et al., 2014). To predict the precise geographical location of sills and overdeepenings with the limited information known for many fjords is a nearimpossible task. However, as described in the previous paragraph, the statistics of these features could be represented by a stochastic model. To the best of our knowledge, our study is the first to consider the statistical properties of fjord bathymetry. This is a significant development as constraining models of high frequency is important where bathymetric surfaces are used to mimic calving (e.g. Lee et al., 2015) or to spin up ice sheet models over larger regions (e.g. Bindschadler et al., 2013). The exponent for the high-frequency tail of the fjord bathymetry power spectrum, 1.74, is consistent with other exponent values found for seafloor topography (Bell, 1975; Goff and Jordan, 1988) and serves as a preliminary guide for future stochastic models. The transition wavelength $(\sim 15 \mathrm{~km})$ for the fjord power spectra is shorter than for abyssal-hill features in the mid-ocean, where the wavelength value is $\sim 40 \mathrm{~km}$ (Bell, 1975).

This paper provides a proof-of-concept routine for constructing geomorphologically realistic fjord geometry in the absence of observations. Actual implementation of the presented routine for large regions (e.g. the Greenlandic coast) would require manual intervention insofar as (i) identifying a seed elevation at the head of the channel and (ii) defining an end zone (e.g. the fjord mouth). Step (i) could be achieved by using a nearest-neighbour approach to acquire the nearest elevation to a given seed location. A solution to step (ii) could be using an observation density grid where the end zone is identified as being a location with an observation density greater than a chosen value. In addition to this, the values necessary to prevent the development of closed-circuit artefacts would have to be adapted to the width of the fjords for which the method is implemented.

\section{Summary}

Until now, bed-bathymetry DEMs for coastal regions of Greenland have been limited by sparse observations and simplistic interpolation methods being applied within fjord regions. The presented algorithm for synthetic fjord bathymetry provides a new approach to generate bathymetric geometry along fjords. The method takes advantage of observational data where available and assumes that fjords maintain a parabolic cross-sectional profile, thus capturing a leading-order geometric constraint from the ice flow geomorphological processes largely responsible for fjord formation. The validity of the algorithm was tested through comparison with new observational bathymetry data for a fjord system in north-west Greenland, and better overall agreement with the data was observed than for Bed2013. Additionally, we performed an initial assessment for how a stochastic model of fjord bathymetry could be parameterised, and thus how high-frequency perturbations to the flat synthetic geometry could be modelled. The physical validity of the algorithm is limited at multiple channel confluences, as the hierarchy of processes responsible for the landscape features is not explicitly incorporated in the algorithm.

Until more observational data are available, this algorithm provides a suitable estimate for simulating previously unmapped fjord geometry. The presented method will be used to assist in the mapping of fjords within the next Greenland bed DEM data product and has potential application for Antarctica. With use of the results of the stochastic model analysis, multiple Greenland bed DEM realisations will be produced, offering the opportunity for the running of ensemble ice sheet model simulations. The release of this new dataset is proposed for 2017.

\section{Data availability}

All data used for the preparation of this manuscript are openly available. The GIMP land classification mask is available and fully documented in Howat et al. (2014). Bed2013 is available and fully documented in Bamber et al. (2013). The IBCAO (v3) DEM is available and fully documented in Jakobsson et al. (2012). The OBS1516 dataset was constructed from (1) the OMG and (2) the Uummannaq and Viagat fjord system bathymetric datasets, which are documented and available from OMG Mission (2016) and Rignot et al. (2016) respectively.

Author contributions. C. N. Williams, T. M. Jordan, J. A. Dowdeswell, M. J. Siegert and J. L. Bamber were involved in the development of the overall methodological framework and interpreted the results. S. L. Cornford and C. N. Williams developed the code to map fjord centrelines. C. N. Williams, C. D. Clark, D. A. Swift and A. Sole were involved in discussions with regard to the introduction of fjord shape and overdeepenings. 
T. M. Jordan and C. N. Williams implemented the processing of the spectral analysis of the fjord profiles. I. Fenty provided part of the OBS1516 dataset. C. N. Williams wrote the manuscript with comments and contributions from all other authors.

Competing interests. J. L. Bamber is a member of the editorial board of the journal. All other authors declare that they have no conflict of interest.

Acknowledgements. This study was supported by UK NERC grant NE/M000869/1.

Edited by: O. Gagliardini

Reviewed by: J. Goff, R. Timmermann, and one anonymous referee

\section{References}

Arndt, J. E., Jokat, W., Dorschel, B., Myklebust, R., Dowdeswell, J. A., and Evans, J.: A new bathymetry of the Northeast Greenland continental shelf: Constraints on glacial and other processes, Geochem. Geophy. Geosy., 16, 3733-3753, doi:10.1002/2015GC005931, 2015.

Bai, X., Latecki, L. J., and Liu, W. Y.: Skeleton pruning by contour partitioning with discrete curve evolution, IEEE T. Pattern Anal., 29, 449-462, doi:10.1109/TPAMI.2007.59, 2007.

Bamber, J. L., Layberry, R. L., and Gogineni, S. P.: A new ice thickness and bed data set for the Greenland ice sheet: 1. Measurement, data reduction, and errors, J. Geophys. Res., 106, 3377333780, doi:10.1029/2001JD900054, 2001.

Bamber, J. L., Griggs, J. A., Hurkmans, R. T. W. L., Dowdeswell, J. A., Gogineni, S. P., Howat, I., Mouginot, J., Paden, J., Palmer, S., Rignot, E., and Steinhage, D.: A new bed elevation dataset for Greenland, The Cryosphere, 7, 499-510, doi:10.5194/tc-7499-2013, 2013.

Batchelor, C. L. and Dowdeswell, J. A.: The physiography of High Arctic cross-shelf troughs, Quaternary Sci. Rev., 92, 6896, doi:10.1016/j.quascirev.2013.05.025, 2014.

Bell, T. H.: Statistical features of sea-floor topography, Deep-Sea Res., 22, 883-892, doi:10.1016/0011-7471(75)90090-X, 1975.

Bindschadler, R. A., Nowicki, S., Abe-OUCHI, A., Aschwanden, A., Choi, H., Fastook, J., Granzow, G., Greve, R., Gutowski, G., Herzfeld, U., Jackson, C., Johnson, J., Khroulev, C., Levermann, A., Lipscomb, W. H., Martin, M. A., Morlighem, M., Parizek, B. R., Pollard, D., Price, S. F., Ren, D., Saito, F., Sato, T., Seddik, H., Seroussi, H., Takahashi, K., Walker, R., and Wang, W. L.: Icesheet model sensitivities to environmental forcing and their use in projecting future sea level (the SeaRISE project), J. Glaciol., 59, 195-224, doi:10.3189/2013JoG12J125, 2013.

Blum, H.: A transformation for extracting new descriptors of shape, in: Models for the Perception of Speech and Visual Form, edited by Wathen-Dunn, W., 362-380, MIT Press, second edn., 1967.

Boghosian, A., Tinto, K., Cochran, J. R., Porter, D., Elieff, S., Burton, B. L., and Bell, R. E.: Resolving bathymetry from airborne gravity along Greenland fjords, J. Geophys. Res.-Sol. Ea., 120, 8516-8533, doi:10.1002/2015JB012129, 2015.
Coles, R. J.: The cross-sectional characteristics of glacial valleys and their spatial variability, $\mathrm{PhD}$ thesis, Univeristy of Sheffield, http://etheses.whiterose.ac.uk/5452/, 2014.

Cook, S. J. and Swift, D. A.: Subglacial basins: Their origin and importance in glacial systems and landscapes, Earth-Sci. Rev., 115, 332-372, doi:10.1016/j.earscirev.2012.09.009, 2012.

Dentith, M. and Mudge, S. T.: Geophysics for the Mineral Exploration Geoscientist, Cambridge University Press, Cambridge, UK, 2014.

Deutsch, C. V. and Journel, A. G.: GSLIB: Geostatistical Software Library and User's Guide, Oxford University Press, Oxford, second edn., 1998.

Dowdeswell, J. A., Hogan, K. A., Ó Cofaigh, C., Fugelli, E. M. G., Evans, J., and Noormets, R.: Late Quaternary ice flow in a West Greenland fjord and cross-shelf trough system: Submarine landforms from Rink Isbrae to Uummannaq shelf and slope, Quaternary Sci. Rev., 92, 292-309, doi:10.1016/j.quascirev.2013.09.007, 2014.

Durand, G., Gagliardini, O., Favier, L., Zwinger, T., and Le Meur, E.: Impact of bedrock description on modeling ice sheet dynamics, Geophys. Res. Lett., 38, L20501, doi:10.1029/2011GL048892, 2011.

Fadlelmula F., M. M., Killough, J., and Fraim, M.: TiConverter: A training image converting tool for multiple-point Geostatistics, Comput. Geosci., 96, 47-55, doi:10.1016/j.cageo.2016.07.002, 2016.

Goff, J. A. and Jordan, T. H.: Stochastic Modeling of Seafloor Morphology' Inversion of Sea Beam Data for Second-Order Statistics, J. Geophys. Res., 93, 13589-13608, doi:10.1029/JB093iB11p13589, 1988.

Goff, J. A. and Nordfjord, S.: Interpolation of Fluvial Morphology Using Channel-Oriented Coordinate Transformation: A Case Study from the New Jersey Shelf, Math. Geol., 36, 643-658, doi:10.1023/b:matg.0000039539.84158.cd, 2004.

Goff, J. A., Powell, E. M., Young, D. A., and Blankenship, D. D.: Conditional simulation of Thwaites Glacier (Antarctica) bed topography for flow models: incorporating inhomogeneous statistics and channelized morphology, J. Glaciol., 60, 635-646, doi:10.3189/2014jog13j200, 2014.

Gogineni, S., Tammana, D., Braaten, D., Leuschen, C., Akins, T., Legarsky, J., Kanagaratnam, P., Stiles, J., Allen, C., and Jezek, K.: Coherent radar ice thickness measurements over the Greenland ice sheet, J. Geophys. Res., 106, 33761-33772, doi:10.1029/2001JD900183, 2001.

Herzfeld, U. C., Wallin, B. F., Leuschen, C. J., and Plummer, J.: An algorithm for generalizing topography to grids while preserving subscale morphologic characteristics-creating a glacier bed DEM for Jakobshavn trough as low-resolution input for dynamic ice-sheet models, Comput. Geosci., 37, 1793-1801, doi:10.1016/j.cageo.2011.02.021, 2011.

Hock, R. and Jensen, H.: Application of Kriging Interpolation for Glacier Mass Balance Computations, Geogr. Ann. A, 81, 611619, doi:10.1111/1468-0459.00089, 1999.

Howat, I. M., Negrete, A., and Smith, B. E.: The Greenland Ice Mapping Project (GIMP) land classification and surface elevation data sets, The Cryosphere, 8, 1509-1518, doi:10.5194/tc-81509-2014, 2014.

Jakobsson, M., Mayer, L. A., Coakley, B., Dowdeswell, J. A., Forbes, S., Fridman, B., Hodnesdal, H., Noormets, R., Peder- 
sen, R., Rebesco, M., Schenke, H. W., Zarayskaya, Y., Accettella, D., Armstrong, A., Anderson, R. M., Bienhoff, P., Camerlenghi, A., Church, I., Edwards, M., Gardner, J. V., Hall, J. K., Hell, B., Hestvik, O. B., Kristoffersen, Y., Marcussen, C., Mohammad, R., Mosher, D., Nghiem, S. V., Pedrosa, M. T., Travaglini, P. G., and Weatherall, P.: The International Bathymetric Chart of the Arctic Ocean (IBCAO) Version 3.0, Geophys. Res. Lett., 39, L12609, doi:10.1029/2012GL052219, 2012.

James, W. H. M. and Carrivick, J. L.: Automated modelling of spatially-distributed glacier ice thickness and volume, Comput. Geosci., 92, 90-103, doi:10.1016/j.cageo.2016.04.007, 2016.

Kienholz, C., Rich, J. L., Arendt, A. A., and Hock, R.: A new method for deriving glacier centerlines applied to glaciers in Alaska and northwest Canada, The Cryosphere, 8, 503-519, doi:10.5194/tc-8-503-2014, 2014.

Korsgaard, N. J., Nuth, C., Khan, S. A., Kjeldsen, K., Bjørk, A. A., and Kjær, K. H.: Digital Elevation Model and orthophotographs of Greenland based on aerial photographs from 1978-1987, Scientific Data, 3, 160032, doi:10.1038/sdata.2016.32, 2016.

Le Brocq, A. M., Payne, A. J., and Vieli, A.: An improved Antarctic dataset for high resolution numerical ice sheet models (ALBMAP v1), Earth Syst. Sci. Data, 2, 247-260, doi:10.5194/essd-2-247-2010, 2010.

Lee, V., Cornford, S. L., and Payne, A. J.: Initialization of an icesheet model for present-day Greenland, Ann. Glaciol., 56, 129_ 140, doi:10.3189/2015AoG70A121, 2015.

Merwade, V., Maidment, D., and Hodges, B.: Geospatial Representation of River Channels, Journal of Hydrological Engineering, 10, 243-251, doi:10.1061/(ASCE)1084-0699(2005)10:3(243), 2005.

Merwade, V., Cook, A., and Coonrod, J.: GIS techniques for creating river terrain models for hydrodynamic modeling and flood inundation mapping, Environ. Modell. Softw., 23, 1300-1311, doi:10.1016/j.envsoft.2008.03.005, 2008

Merwade, V. M., Maidment, D. R., and Goff, J. A.: Anisotropic considerations while interpolating river channel bathymetry, J. Hydrol., 331, 731-741, doi:10.1016/j.jhydrol.2006.06.018, 2006.

Morlighem, M., Rignot, E., Seroussi, H., Larour, E., Ben Dhia, H., and Aubry, D.: A mass conservation approach for mapping glacier ice thickness, Geophys. Res. Lett., 38, L19503, doi:10.1029/2011g1048659, 2011.

Morlighem, M., Rignot, E., Mouginot, J., Seroussi, H., and Larour, E.: Deeply incised submarine glacial valleys beneath the Greenland ice sheet, Nat. Geosci., 7, 418-422, doi:10.1038/ngeo2167, 2014.

Murray, T., Scharrer, K., James, T. D., Dye, S. R., Hanna, E., Booth, A. D., Selmes, N., Luckman, A., Hughes, A. L. C., Cook, S., and Huybrechts, P.: Ocean regulation hypothesis for glacier dynamics in southeast Greenland and implications for ice sheet mass changes, J. Geophys. Res., 115, F03026, doi:10.1029/2009jf001522, 2010.

OMG Mission. Bathymetry (sea floor depth) data from the shipbased bathymetry survey. Ver. 0.1. OMG SDS, CA, USA, available at: http://dx.doi.org/10.5067/OMGEV-BTYSS (last access: 30 August 2016), 2016.

Patton, H., Swift, D. A., Clark, C. D., Livingstone, S. J., Cook, S. J., and Hubbard, A.: Automated mapping of glacial overdeepenings beneath contemporary ice sheets: Approaches and potential applications, Geomorphology, 232, 209-223, doi:10.1016/j.geomorph.2015.01.003, 2015.

Patton, H., Swift, D. A., Clark, C. D., Livingstone, S. J., and Cook, S. J.: Distribution and characteristics of overdeepenings beneath the Greenland and Antarctic ice sheets: Implications for overdeepening origin and evolution, Quaternary Sci. Rev., 148, 128-145, doi:10.1016/j.quascirev.2016.07.012, 2016.

Rignot, E., Fenty, I., Xu, Y., Cai, C., Velicogna, I., Cofaigh, C. O., Dowdeswell, J. A., Weinrebe, W., Catania, G., and Duncan, D.: Bathymetry data reveal glaciers vulnerable to ice-ocean interaction in Uummannaq and Vaigat glacial fjords, west Greenland, Geophys. Res. Lett., 43, 2667-2674, doi:10.1002/2016GL067832, 2016.

Schaffer, J., Timmermann, R., Arndt, J. E., Kristensen, S. S., Mayer, C., Morlighem, M., and Steinhage, D.: A global, high-resolution data set of ice sheet topography, cavity geometry, and ocean bathymetry, Earth Syst. Sci. Data, 8, 543-557, doi:10.5194/essd8-543-2016, 2016.

Schjøth, F., Andresen, C. S., Straneo, F., Murray, T., Scharrer, K., and Korablev, A.: Campaign to map the bathymetry of a major Greenland fjord, Eos Transactions AGU, 93, 141-142, doi:10.1029/2012EO140001, 2012.

Seroussi, H., Morlighem, M., Rignot, E., Larour, E., Aubry, D., Ben Dhia, H., Kristensen, S. S., Dhia, H. B., and Kristensen, S. S.: Ice flux divergence anomalies on 79north Glacier, Greenland, Geophys. Res. Lett., 38, L09501, doi:10.1029/2011GL047338, 2011.

Shepard, M. K., Brackett, R. A., and Arvidson, R. E.: Selfaffine ( fractal ) topography : Surface parameterization and radar scattering Radar, J. Geophys. Res., 100, 11709-11718, doi:10.1029/95JE00664, 1995.

Shepard, M. K., Campbell, B. A., Bulmer, M. H., Farr, T. G., Gaddis, L. R., and Plaut, J. J.: The roughness of natural terrain: A planetary and remote sensing perspective, J. Geophys. Res.Planet., 106, 32777-32795, doi:10.1029/2000JE001429, 2001.

Strahler, A. N.: Quantitative Analysis of Watershed Geomorphology, Transactions, American Geophysical Union, 38, 913-920, doi:10.1029/TR038i006p00913, 1957.

Straneo, F., Curry, R. G., Sutherland, D. A., Hamilton, G. S., Cenedese, C., Våge, K., and Stearns, L. A.: Impact of fjord dynamics and glacial runoff on the circulation near Helheim Glacier, Nat. Geosci., 4, 322-327, doi:10.1038/ngeo1109, 2011.

Sun, S., Cornford, S. L., Liu, Y., and Moore, J. C.: Dynamic response of Antarctic ice shelves to bedrock uncertainty, The Cryosphere, 8, 1561-1576, doi:10.5194/tc-8-1561-2014, 2014.

Syvitski, J. P., Burrell, D. C., and Skei, J. M.: Fjords: Processes and Products, Springer, Berlin, doi:10.1007/978-1-4612-4632-9, 1987.

Tyan, F., Hong, Y.-F., Tu, S.-H., and Jeng, W. S.: Generation of random road profiles, J. Adv. Eng., 4, 1373-1378, 2009.

Van Der Walt, S., Colbert, S. C., and Varoquaux, G.: The NumPy array: A structure for efficient numerical computation, Comput. Sci. Eng., 13, 22-30, doi:10.1109/MCSE.2011.37, 2011.

Van Der Walt, S., Schönberger, J. L., Nunez-Iglesias, J., Boulogne, F., Warner, J. D., Yager, N., Gouillart, E., and Yu, T.: scikit-image: image processing in Python, PeerJ, 2, e453, doi:10.7717/peerj.453, 2014. 
Vieli, A. and Nick, F.: Understanding and Modelling Rapid Dynamic Changes of Tidewater Outlet Glaciers: Issues and Implications, Surv. Geophys., 32, 437-458, doi:10.1007/s10712-0119132-4, 2011.
Wheeler, D.: Using parabolas to describe the cross-sections of glaciated valleys, Earth Surf. Proc. Land., 9, 391-394, doi:10.1002/esp.3290090412, 1984. 